\title{
Frequency Control of Smart Base Isolation System Employing A Novel Adaptive Magneto-rheological Elastomer Base Isolator
}

\author{
Xiaoyu Gu, Jianchun Li*, Yancheng Li and Mohsen Askari
}

\begin{abstract}
In the past decades, base isolation techniques have become increasingly popular for seismic protection of civil structures owing to its capability of decoupling buildings from harmful ground motion. However, it has been recognised recently the traditional passive base isolation technique could encounter a serious problem during earthquakes due its incapability in adjusting the isolation frequency to cope with the unpredictability and diversity of earthquakes. To address this challenge, a great deal of research efforts have been conducted to improve traditional base isolation systems, most of which focused on hybrid supplementary devices (passive, active and semi-active types) for the isolators to control displacement or to dissipate seismic energy. On the other hand, the most effective approach to address the aforementioned challenge should lay on varying isolator stiffness in real-time to achieve real-time spontaneous decoupling. A recent advance of the development of an adaptive magneto-rheological elastomer (MRE) base isolator has brought such idea to reality as the new MRE base isolator is capable to alter its stiffness significantly in real-time.
\end{abstract}

In this paper, an innovative smart base isolation system employing such MRE isolator is proposed and a novel frequency control algorithm is developed to shift the fundamental frequency of the structure away from the dominant frequency range of earthquakes. Such design enables the building to avoid resonant state in real-time according to the on-coming spectrum of the earthquakes. Extensive simulation has been conducted using a 5-storey benchmark model with the isolation system and testing results indicate that the proposed control system is able to significantly suppress both the floor accelerations and inter-storey drifts simultaneously under different earthquakes.

\section{Keywords}

Magneto-rheological elastomer, adaptive base isolator, modelling, frequency control, 5-storey benchmark model

\section{Introduction}

Base isolation systems, first appearing in 1909 (Symans and Constantinou, 1999), have been accepted as the most effective earthquake resistant strategy and widely adopted (Jangid and Datta, 1995). Despite the fact that traditional base isolation system proved to be effective in mitigating harmful vibrations of different key civil infrastructures, its efficiency and robustness are greatly in danger resulting from the lack of adaptability and flexibility to the unpredictable and diverse source vibration caused by its inherent passive nature (Kelly, 1999; Massa and Vulcano, 2012). As a result, once designed and installed, the passive system is incapable of adjusting its own properties to cope with the changes in the structure or earthquake (Spencer and Nagarajaiah, 2003).

To overcome the shortcomings of passive base isolations, various methods, classified as hybrid base isolation systems, have been proposed and explored by the researchers to reduce the seismic response of a building by adding supplementary energy-dissipation or displacement control members. Yoshioka et al. (2002) and Ramallo et al. (2002) proposed combination of conventional base isolators and controllable dampers, to compensate the traditional base isolation system for extreme earthquakes. Wongprasert et al. (2005) experimentally evaluated a combined spherical sliding bearings and variable fluid damper system for a multi-story building frame. However, some additional problems may be raised by simply adding supplementary devices (Massa and Vulcano, 2012). For instance, although effectively reducing the displacement, attached passive or controllable damper may lead to the increase of the isolated structure's floor acceleration due to the higher mode vibration mode contributions. Additionally, hybrid base isolation systems increase complexity to the design and implementation of the base isolation system. Moreover, the hybrid systems proposed so far are unable to deal with far-field earthquakes because

Centre for Built Infrastructure Research, Faculty of Engineering and IT, University of Technology, Sydney, Australia

Corresponding author:

Professor Jianchun Li, Centre for Built Infrastructure Research, Faculty of Engineering and IT, University of Technology, Sydney, NSW 2007, Australia

Email: Jianchun.li@uts.edu.au 
isolators themselves are still in passive nature and the supplementary devices cannot adjust natural frequency of the isolators to decouple incoming excitations.

As an attempt to address the challenges facing the current base isolation practice, $\mathrm{Li}$ et al. (Li et al., 2012; Li et al., 2013a, 2013b) designed and manufactured the world's first full-scale base isolator utilising a smart material named magneto-rheological elastomer (MRE) whose elastic modulus increases monotonically with the magnetic field. Such unique property of controllable stiffness endows the MRE base isolator with real-time controllability on stiffness, which has enlightened a potential solution of the major shortcomings in the traditional base isolations. The developed MRE base isolator adopted a unique sandwich structure of laminated MRE layers and steel plates, imitating the classic laminated rubber bearing. The researchers sought to improve the performance of the MRE isolator, providing it with a large range of stiffness under applied magnetic fields. This was accomplished by improving their design by employing a new MRE material and ameliorating the manufacturing process ( $\mathrm{Li}$ et al. 2015). Experimental results indicate that this novel MRE base isolator exhibits good performance with a great increase of stiffness (more than 16 folds) under applied magnetic field. A novel control system better exploiting MRE base isolator's unique property is then in great need.

Inspired by a simple but effective control method proposed by Kobori et al. (1993) for AVS system, a new control method, known as the frequency control, has been developed especially for better utilising the characteristics of MRE isolator, aiming at altering the structural stiffness and frequency to avoid resonance. By adjusting the input current of the MRE isolator, the structural matrices will be changed in accordance with the changes of the stiffness and damping properties of the isolator, which will result in the changes of the natural frequency of each dynamic mode of the system. This control method is to generate the current that will alter the stiffness of the structure as far away as possible from the predominant frequency of the earthquake. The proposed control system is made up of 4 primary units. Earthquake excitations will be measured by the accelerometers in the first unit and then input to the motion anticipating analysers in the second unit. The response of each stiffness scenario will be forecasted by the analysers and then forwarded to the control decision processor. Judged by the control law, the best stiffness scenario will be chosen and the control signal will be sent to the MRE isolators to change the structure's state. The control system endeavours to produce a non-stationary, non-resonant condition changing continuously during the earthquake attack. By maintaining the non-resonant condition, the method can isolate the seismic energy from transmitting into the building.

This paper firstly examines the magneto-rheological elastomer (MRE) base isolator, such as its design and performance. The performance of MRE base isolator was summarized and mathematical models were established to capture its behaviour. A five-storey benchmark building model has been utilised for numerical evaluation of this design. In the following section, the mechanism of the proposed frequency control method is introduced in detail, followed by extensive theoretical analysis. Simulation results indicate that the seismic resistance of the building with a frequency controlled smart base isolation system is significantly superior to the bare frame and building with passive base isolation system under different types of earthquakes, which are scaled benchmark earthquakes of El-Centro 1940, Kobe 1995, Hachinohe 1968 and Northridge 1994.

\section{Modelling of novel adaptive MRE base isolator}

\section{Material description}

The key material in novel adaptive base isolator is an intelligent rubber named magneto-rheological elastomer. It possesses real-time controllable shear modulus and damping. The MR effect, whereby the shear modulus varies depending on the applied magnetic field, is integral to the design of the MRE base isolator. Comprehensive studies have been conducted ( $\mathrm{Li}$ et al., 2013a, 2013b) to optimise the material design and maximise the MR effect to achieve the largest stiffness range to meet the adaptively working requirements under various and unpredictable earthquakes. The composition of the MR elastomers adopted in this isolator are $70 \mathrm{w} \%$ carbonyl iron particles with diameter between 3 and $5 \mu \mathrm{m}, 15 \mathrm{w} \%$ silicon rubber and $15 \mathrm{w} \%$ silicone oil with a density of $7.86 \mathrm{~g} / \mathrm{cm}^{3}, 1.04$ $\mathrm{g} / \mathrm{cm}^{3}$ and $0.96 \mathrm{~g} / \mathrm{cm}^{3}$ respectively.

\section{Design of adaptive MRE base isolator}

Li et al. (2013b) designed and manufactured a highly adjustable adaptive MRE base isolator from a traditional laminated rubber bearing structure. By substituting the ordinary rubber element with the new soft MR elastomer, this new design of MRE isolator is able to overcome the shortcomings of the traditional laminated rubber bearing caused by its intrinsic passive property. The core of the isolator is a laminated structure with a diameter of $120 \mathrm{~mm}$ consisting of 25 one-millimetre-thick MRE layers interwoven in between 24 one-millimetre-thick steel layers in an adjacent arrangement.

The laminated MRE bearing core (Figure 1) is placed inside a solenoid, which is to generate uniformed magnetic field when electrified by DC current. Space between the laminated MRE rubber core and the solenoid allows a maximum 15 millimetres lateral deformation.

The performance of the MRE adaptive base isolator has been evaluated and characterised by extensive experimental testing. In the cycling testing, the isolator was loaded with harmonic inputs with controlled displacement of various frequencies of $0.1,1.0,2.0$ and $4.0 \mathrm{~Hz}$. In each loading scenario, the MRE base isolator was energised by 4 different current levels (0,1, 2 and 3A) to stimulate different magnetic field. The change of isolator's stiffness and damping value with applied current under different 
external excitations when deformation is $4 \mathrm{~mm}$ is presented in Table 1 and 2. The shear force-displacement graphs (Figure 2) under cyclic loading of $4 \mathrm{~mm}$ shear displacement and $4.0 \mathrm{~Hz}$ shows that the MRE base isolator possesses large stiffness change when applied with different currents.

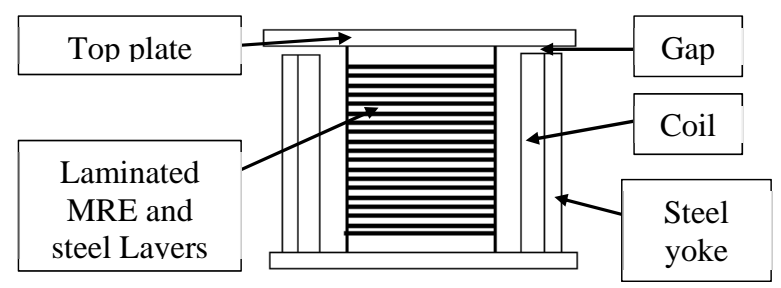

(a)

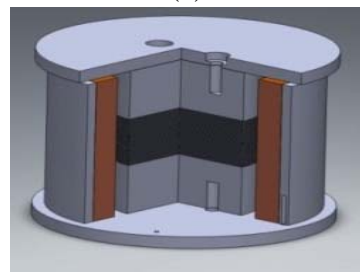

(b)

Figure 1 (a) Cross-section view of MRE isolator

(b) Schematics of MRE isolator

Table 1. Effective stiffness of the MRE base isolator

\begin{tabular}{ccccc}
\hline Effective Stiffness & \multicolumn{4}{c}{$\Delta=\mathbf{4} \mathbf{~ m m}$} \\
\cline { 2 - 5 } (Normalized, kNm $^{-1}$ ) & $\mathbf{0 . 1} \mathbf{~ H z}$ & $\mathbf{1 . 0 ~} \mathbf{~ z z}$ & $\mathbf{2 . 0 ~} \mathbf{~ z z}$ & $\mathbf{4 . 0 ~} \mathbf{~ z}$ \\
\hline $0.0 \mathrm{~A}$ & 3.63 & 4.69 & 5.33 & 6.43 \\
1.0 A & 19.35 & 20.72 & 20.87 & 21.07 \\
2.0 A & 33.73 & 38.15 & 37.53 & 37.25 \\
$3.0 \mathrm{~A}$ & 46.64 & 48.74 & 47.88 & 47.72 \\
Increase (0-3 A) (\%) & 1186 & 939 & 798 & 642 \\
\hline
\end{tabular}

Table 2. Equivalent damping of the MRE base isolator

\begin{tabular}{ccccc}
\hline \multirow{2}{*}{$\begin{array}{c}\text { Damping Coefficient } \\
\left(\mathbf{~ k N s m}^{-1}\right)\end{array}$} & $\mathbf{0 . 1} \mathbf{H z}$ & $\mathbf{1 . 0} \mathbf{~ H z}$ & $\mathbf{2 . 0 ~} \mathbf{~ H z}$ & $\mathbf{4 . 0} \mathbf{~ H z}$ \\
\cline { 2 - 5 } & 1.67 & 0.33 & 0.21 & 0.14 \\
$0.0 \mathrm{~A}$ & 12.46 & 1.50 & 0.81 & 0.46 \\
$1.0 \mathrm{~A}$ & 20.75 & 2.50 & 1.31 & 0.73 \\
$2.0 \mathrm{~A}$ & 26.04 & 2.94 & 1.53 & 0.85 \\
$3.0 \mathrm{~A}$ & & & & \\
\hline
\end{tabular}

Strain stiffening model

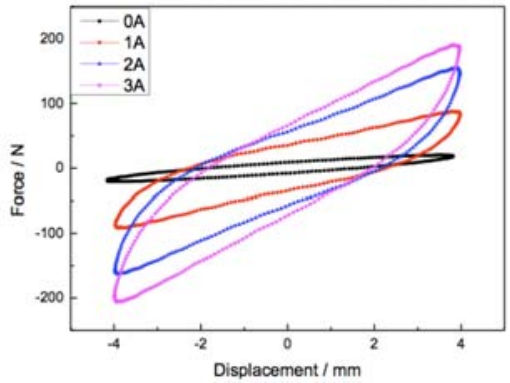

Figure 2 Shear force-displacement graphs of MRE isolator

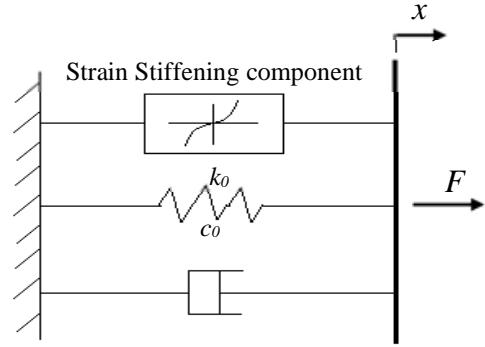

Figure 3 Proposed strain-stiffening model

A strain-stiffening model has been proposed in this work, shown in Figure 3. The model contains a spring, a viscous damper and a strain-stiffening component in a parallel connection. The shear force $F$ generated by the MRE isolator is a function of time $t$ and input current $I$ and can be expressed as:

$$
F(I, t)=k_{0}(I) \cdot x(t)+c_{0}(I) \cdot \dot{x}(t)+\alpha(I) \cdot x(t)^{3}
$$

Where $x$ and $\dot{x}(t)$ are the displacement and velocity of the MRE isolator while the coefficients $k_{0}, c_{0}$ and $\alpha$ are all functions of input current $I$, which represent the stiffness, damping and the coefficient of the strainstiffening component. The expressions of $k_{0}, c_{0}$ and $\alpha$ can be given as:

$$
\begin{gathered}
k_{0}(I)=8.062 \cdot I+4.523 \\
c_{0}(I)=-0.0994 \cdot I^{2}+0.7598 \cdot I+0.2028 \\
\alpha(I)=-0.1232 \cdot I^{2}+0.7366 \cdot I+0.007065
\end{gathered}
$$

Five storey benchmark structure with adaptive base isolator

System description

\section{1) Equations of motion}

A smart base isolation system (Figure 4) is established by interposing the adaptive MRE base isolator underneath the civil structure. The base-isolated structure with bare frame of $n$-storey has $n+1$ degree-of-freedom.. Given the acceleration of ground motion is $\ddot{x}_{g}(t)$, the equation of the structure's motion can be given as:

$$
\boldsymbol{M} \ddot{\boldsymbol{x}}(t)+\boldsymbol{C} \dot{\boldsymbol{x}}(t)+\boldsymbol{K} \boldsymbol{x}(t)=\boldsymbol{D} \boldsymbol{u}(t)+\boldsymbol{M r} \ddot{\boldsymbol{x}}_{\boldsymbol{g}}(t)
$$

Where $\mathbf{M}, \mathbf{C}$ and $\mathbf{K}$ are the $(\mathrm{n}+1) \times(\mathrm{n}+1)$ mass, damping and stiffness matrices, respectively; $\boldsymbol{x}(\mathrm{t}), \dot{\boldsymbol{x}}(\mathrm{t})$ and $\ddot{\boldsymbol{x}}(\mathrm{t})$ refer to the $(n+1)$ dimensional column vectors of relative displacement, velocity and acceleration; $\boldsymbol{u}(\mathrm{t})$ is the vector of control force. Furthermore, $\mathbf{D}$ is the location matrix of control force while $\boldsymbol{r}$ is the location matrix of earthquake excitation. Since the base isolators are only installed in the base floor, $\mathbf{D}_{(\mathbf{n}+\mathbf{1}) \times \mathbf{1}}$ and $\boldsymbol{r}_{(\mathbf{n}+\mathbf{1}) \times \mathbf{1}}$ can be given as

$$
\mathbf{D}=[1,0,0, \ldots, 0]^{\mathbf{T}}
$$



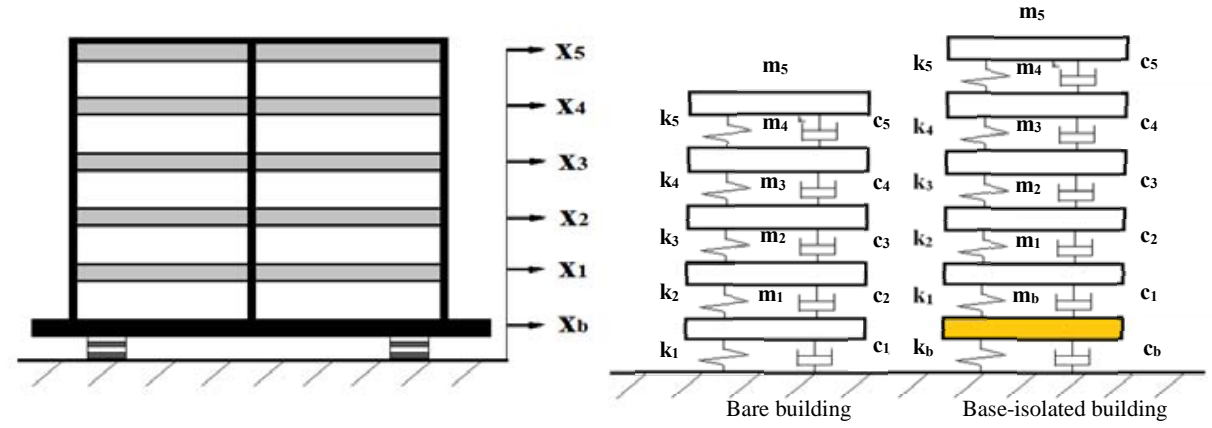

Figure 4. Sketch and schematics of the smart base isolation system

$$
\boldsymbol{r}=[1,1,1, \ldots, 1]^{\mathbf{T}}
$$

In state-space, equation (5) can be converted to

$$
\dot{\mathbf{z}}(t)=\boldsymbol{A z}(t)+\boldsymbol{B} \boldsymbol{u}(t)+\boldsymbol{H} \ddot{\boldsymbol{x}}_{\boldsymbol{g}}(t), \quad \boldsymbol{z}(0)=\boldsymbol{z}_{\mathbf{0}}(8)
$$

Where $\boldsymbol{z}(\mathrm{t})$ is a $2(\mathrm{n}+1)$ dimensional column state vector, $\mathbf{A}$ is the $2(n+1) \times 2(n+1)$ system matrix, $\mathbf{B}$ and $\mathbf{H}$ are the location matrices respectively determining the location of controllers and external excitations, which can be written as

$$
\begin{gathered}
\boldsymbol{z}(t)=\left[\begin{array}{l}
\boldsymbol{x}(t) \\
\dot{\boldsymbol{x}}(t)
\end{array}\right] \\
\boldsymbol{A}=\left[\begin{array}{cc}
\mathbf{0} & \boldsymbol{I} \\
-\boldsymbol{M}^{-1} \boldsymbol{K} & -\boldsymbol{M}^{-1} \boldsymbol{C}
\end{array}\right] \\
\boldsymbol{B}=\left[\begin{array}{c}
\mathbf{0} \\
\boldsymbol{M}^{-1} \boldsymbol{D}
\end{array}\right] \quad \text { and } \quad \boldsymbol{H}=\left[\begin{array}{c}
\boldsymbol{I} \\
\boldsymbol{M}^{-1} \boldsymbol{r}
\end{array}\right]
\end{gathered}
$$

\section{2) A five-storey benchmark building model}

To demonstrate the effectiveness of the proposed system, a five-storey benchmark model building (Samali et al., 1999) is adopted for analysis and experimental testing. The selfweight of the building model is approximately one ton. Four MRE base isolator ( $\mathrm{Li}$ et al., 2013b) are installed underneath the structure to form adaptive base isolation system. The 5-storey benchmark building model's mass, effective stiffness and damping coefficients are summarized below. Details of the modal identification can be found in the reference (Djajakesukma, 2003).

Table 3. Structural parameters of the 5-storey building

\begin{tabular}{cccccc}
\multicolumn{7}{c}{ model } \\
\hline Floor No. & $\mathbf{1}$ & $\mathbf{2}$ & $\mathbf{3}$ & $\mathbf{4}$ & $\mathbf{5}$ \\
\hline $\begin{array}{c}\text { Mass } \\
(\mathrm{kg})\end{array}$ & 214 & 207 & 207 & 207 & 207 \\
$\begin{array}{c}\text { Stiffness } \\
(\mathrm{kN} / \mathrm{m})\end{array}$ & 1146 & 3124 & 3156 & 3156 & 2978 \\
$\begin{array}{c}\text { Damping } \\
(\mathrm{kN} \cdot \mathrm{s} / \mathrm{m})\end{array}$ & 0.0584 & 0.1117 & 0.1128 & 0.1100 & 0.1233 \\
\hline
\end{tabular}

3) Stiffness type of the smart base isolation system

When alternating the electric current, the stiffness, damping and strain-stiffening coefficient of the base floor, which consists of the MRE isolator, is changed and consequently changes the natural frequencies of the system. The mass, stiffness and damping coefficients of the base level when the applied current varies from $0 \mathrm{~A}$ to $3 \mathrm{~A}$ are listed in Table 4. The corresponding frequencies of all modes are illustrated in Table 5.

Table 4. The mass, stiffness and damping properties of MRE base isolator

\begin{tabular}{ccccc}
\hline Current & Mass & Stiffness & Damping & $\boldsymbol{\alpha}$ \\
\hline $\mathbf{0 A}$ & \multirow{2}{*}{100} & 18.09 & 0.8112 & 0.007065 \\
$\mathbf{3 A}$ & & 114.84 & 6.3504 & 1.108065 \\
\hline
\end{tabular}

Table 5. Natural frequencies of each mode

\begin{tabular}{ccccccc}
\hline Modal No. & $\mathbf{1}$ & $\mathbf{2}$ & $\mathbf{3}$ & $\mathbf{4}$ & $\mathbf{5}$ & $\mathbf{6}$ \\
\hline Bare & 4.28 & 13.54 & 23.31 & 31.63 & 37.29 & - \\
$\mathbf{3 A}$ & 1.75 & 10.92 & 17.75 & 23.97 & 31.78 & 37.31 \\
$\mathbf{0 A}$ & 1.14 & 10.41 & 18.06 & 24.30 & 31.80 & 37.31 \\
\hline
\end{tabular}

Proposed control algorithm for adaptive base isolation

Kobori et al. (1993) have proposed a control method for an active variable stiffness (AVS) system to select optimal structural stiffness to avoid resonance. Based on this method, a control algorithm has been tailored specially for the adaptive MRE base isolator. The input current of the MRE base isolator can be switched between 3A and 0A in accordance with the control signal, therefore providing the structure an optimised non-resonant condition at every instant.

\section{1) Control system flow chart}

The control system mainly consists of 4 parts: (1) earthquake measurement unit, (2) motion anticipating unit, (3) control decision processor and (4) smart base isolation system. Figure 5 displays the working flow chart of the control system.

Four steps will be executed during every control interval. During an earthquake, the accelerometers in earthquake measurement unit capture the ground motion acceleration and send the earthquake signal to the motionanticipating unit. The analysers in the motion-anticipating unit calculate the approximate corresponding responses of each stiffness scenario ( $0 \mathrm{~A}$ and $3 \mathrm{~A})$. Based on the anticipated output, the control decision processor choose the stiffness type which cause the smallest structure 


\begin{tabular}{|c|c|c|c|c|c|c|}
\hline $\begin{array}{c}\text { Earthquake } \\
\text { Measurement Unit }\end{array}$ & $\Longleftrightarrow$ & $\begin{array}{c}\text { Motion } \\
\text { Anticipating Unit }\end{array}$ & $\Longleftrightarrow$ & $\begin{array}{c}\text { Control } \\
\text { Decision Processor }\end{array}$ & $\Longleftrightarrow$ & $\begin{array}{c}\text { Smart Base } \\
\text { Isolation System }\end{array}$ \\
\hline $\begin{array}{l}\text { Measuring: } \\
\text { Ground motion } \\
\text { acceleration }\end{array}$ & & $\begin{array}{c}\text { Evaluating Response: } \\
\text { Scenario } 1 \text { (3A) } \\
\text { Scenario } 2(0 \mathrm{~A})\end{array}$ & & $\begin{array}{l}\text { Scenario Selection: } \\
\text { Judge and adjust the } \\
\text { input current }\end{array}$ & & $\begin{array}{c}\text { Change Stiffness: } \\
\text { Change the structural } \\
\text { frequencies }\end{array}$ \\
\hline
\end{tabular}

Figure 5. Flow chart of the feed-forward frequency control system

responses according to the stiffness scenario selection algorithm discussed in next section. Finally, the control signals (current adjusting command) generated by the control decision processor will be forwarded to the MRE base isolator so that the frequency of the structure can be alternated in real-time. In this method, each control interval takes $0.005 \mathrm{~s}$.

\section{2) Formulae of stiffness scenario selection}

The motion anticipating analysers is to forecast the uncontrolled structural response of each stiffness type i $(i=1,2)$ based on the present state of the subject.. In this work, acceleration, relative displacement and inter-storey drift are used as the evaluative subjects. Therefore, $j$, the number of evaluative subjects varies from 1 to $3 . E_{i, j}(t)$ is the evaluation in terms of the evaluative subject $j$ of the scenario i, which can be written as:

$$
E_{i, j}(t)=e_{i, j} \sqrt{\frac{\sum_{n=1}^{N}\left(R_{i, j}(t-\Delta t \cdot n+\Delta t)\right)^{2}}{N}}
$$

Where $e_{i, j}$ is a coefficient for scenario i reflecting the maximum amplitude of the subject $\mathrm{j}$ corresponding to the resonant frequency of the scenario; $R_{i, j}$ is the output of the subject $\mathrm{j}$ from the motion anticipating analyser; $\Delta t$ is the control interval; $N=t_{i} /(2 \Delta t)$ represents the number of control interval samplings during half of the fundamental period of scenario i.

By calculating $E_{i, j}(t)$ obtains the uncontrolled response of each stiffness scenario in terms of the proximity of the instant of interest. This index is robust because $E_{i, j}(t)$ includes the average output of the motion anticipating analysers during half scenario i’s corresponding fundamental period and also times the average value with the maximum resonant amplitude $e_{i, j}$.

Next, the decision of which stiffness scenario is to be chosen has to be made based on the calculation of the judgment index $J_{i}(t)$ which can be formed as:

$$
\begin{array}{r}
J_{i}(t)=\sum_{j=1}^{2}\left(\frac{E_{i, j}(t)}{\max _{j}\left(\max _{i}\left(E_{i, j}(t)\right)\right)}+\right. \\
\left.\frac{E_{i, j}\left(t+t^{\prime}\right) \max _{i} E_{i, j}(t)}{\max _{i}\left(E_{i, j}\left(t+t^{\prime}\right)\right) \max _{j}\left(\max _{i}\left(E_{i, j}(t)\right)\right)}\right)
\end{array}
$$

$J_{i}(t)$ consists of two terms, of which the first item represents the ratio between the evaluation of a certain subject in a certain scenario and the maximum evaluation of all the subjects in every scenario while the second item reflects the increasing and decreasing trend of the evaluation $E_{i, j}(t)$. In the end, the stiffness scenario with minimum value of index $J_{i}(t)$ will be selected to operate during the next control interval.

\section{3) Control law}

Since there are only two types of stiffness scenario corresponding to two current inputs, the control law for the current $I(\mathrm{t})$ can be described as:

$$
I(t)=\left\{\begin{array}{l}
3 A, J_{3 A}(t)<J_{0 A}(t) \\
0 A, J_{3 A}(t) \geq J_{0 A}(t)
\end{array}\right.
$$

Thus, the control force generated by the MRE adaptive isolator can be written as

$$
\begin{aligned}
u(t)= & k_{0}(I(t)) \cdot x(t)+c_{0}(I(t)) \cdot \dot{x}(t) \\
& +\alpha(I(t)) \cdot x(t)^{3}
\end{aligned}
$$

\section{Results and discussion}

Comparative simulation analysis are conducted between the building model without isolation system, building with passive isolation system and building with smart base isolation system in order to evaluate the performance of the frequency controlled base isolation system. Four scaled benchmark earthquakes were utilised as the external excitation inputs, i.e. El Centro 1940, Kobe 1995, Hachinohe 1968 and Northridge 1994. The earthquakes have been scaled by a factor of 1.7 in terms of time so that the fundamental frequency of the bare building is set within the predominant frequency range of the earthquakes. Therefore, the response of the bare building will be intensified to better demonstrate the effectiveness of the smart base isolation system. 


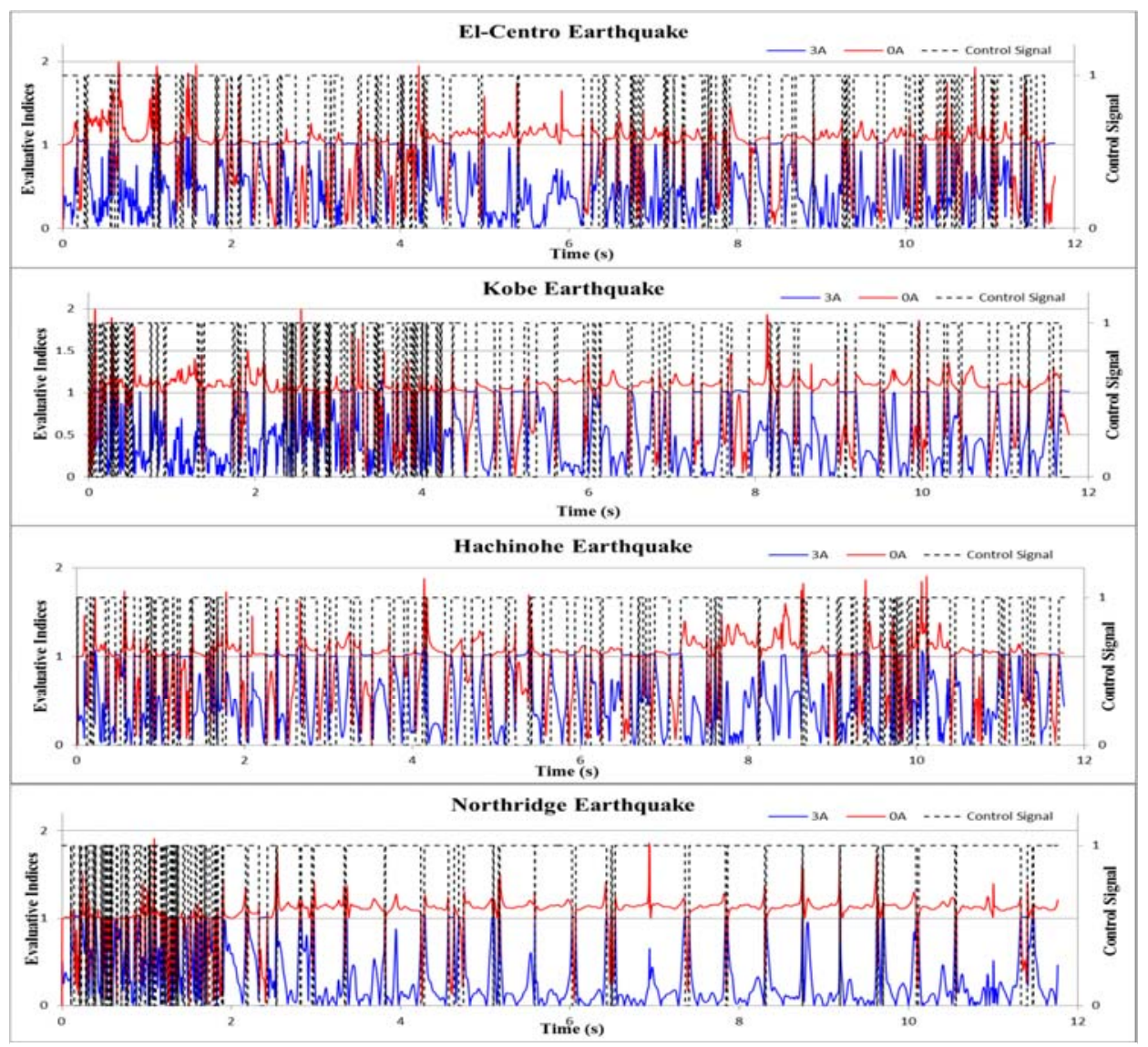

Figure 6. Evaluative indices and control signal within the first 4000 control intervals under 4 earthquakes

Figure 6 records the evaluation indices of the stiffness scenarios when the input current is $0 \mathrm{~A}$ and $3 \mathrm{~A}$, respectively during the time of the first 4000 control intervals. The time histories of the control signal with value 1 representing current of $3 \mathrm{~A}$ and value 0 representing current of $0 \mathrm{~A}$ are also displayed in Figure 6.

Three different indices, referring to the root mean square (RMS) of acceleration, RMS of inter-storey drift of each floor and base shear force, respectively, are introduced to assess the effectiveness of the base-isolated structures, which can be written as

$$
\begin{gathered}
I_{1}=\frac{\max _{t}\left|\sigma_{a i}(t)\right|}{\sigma_{a i}^{\max }} \\
I_{2}=\frac{\max _{t}\left|\sigma_{d i}(t)\right|}{\sigma_{d i}^{\max }} \\
I_{3}=\frac{\max _{t}\left|\sum_{i} m_{i} \ddot{x}_{a}(t)\right|}{F_{b}^{\max }}
\end{gathered}
$$

Where $\sigma_{a i}(t)$ and $\sigma_{d i}(t)$ are the isolated buildings' RMS acceleration and RMS inter-storey drift of the i-th floor over the time history, while $\sigma_{\mathrm{ai}}^{\max }$ and $\sigma_{\mathrm{di}}^{\max }$ are the RMS acceleration and RMS the inter-storey drift of the corresponding floor of the uncontrolled building model. $F_{b}^{\max }$ is the maximum base shear of the bare frame. Tables 6 lists the specific values of $\boldsymbol{I}_{1}$ to $\boldsymbol{I}_{3}$ of the passive base-

isolated and the frequency controlled base-isolated buildings under 4 earthquakes.

Generally, the top floor will witness the largest acceleration and relative displacement during the entire time history. Thus, variations of acceleration and interstorey drift when the acceleration and displacement occur at the 5th floor are adopted to evaluate the vibration intensity.

The time histories of the acceleration at the 5th floor in 3 cases under different earthquakes are shown in Figure 7. It can be clearly observed that the smart base isolation system with frequency control obtains the smallest acceleration response under all 4 earthquakes. The passive base-isolated building also show the reduction in acceleration to some extent compared to the bare building, for instance, during Northridge earthquake. However, the performance of the passive system is greatly affected by the characteristics of the earthquake. The controlled base isolation system proves to be more effective than the passive one in suppressing the acceleration response during the entire time range, particularly in Hachinohe and ElCentro earthquakes, where the response of the passive system exceeds that of the bare frame.

Figure 7 also contains the variations of accelerations with the floor height when the peak acceleration occurs at the top floor. As shown in all variations, the acceleration of 

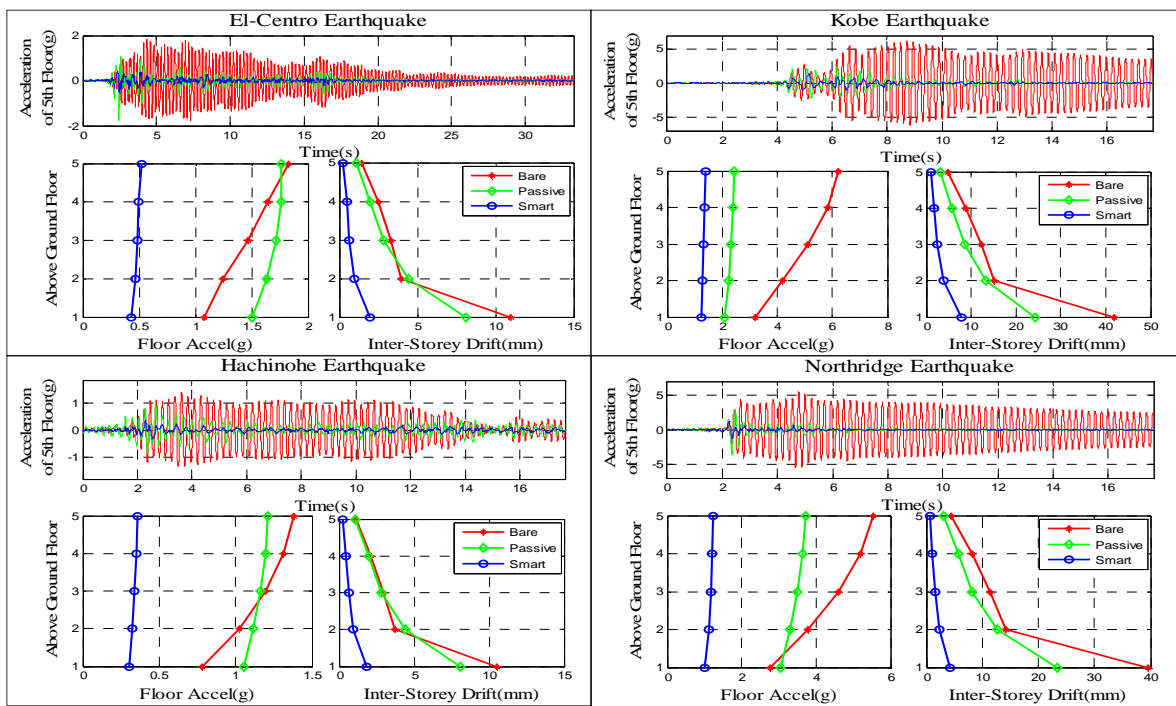

Figure 7 Time histories of acceleration of the 5th floor, variations of accelerations (peak acceleration@ @op floor) and inter-storey drifts (peak drift @ top floor) under 4 earthquakes the bare building increases with the floor height. The acceleration of each floor in the controlled building is significantly reduced compared to the bare building under all earthquakes. The passive base isolated building shows good performance under Kobe earthquake but under other 3 earthquakes, the accelerations at each floor of the passive base-isolated building are not only larger than the controlled building's but also exceed the bare building in some floors. Under different earthquakes, the shapes of the acceleration graphs of the passive base-isolated building are different, which demonstrates a strong dependence on the external excitation, resulting from its inherent passive nature. Furthermore, under all earthquakes, accelerations of all floors in the frequency controlled base-isolated building are almost the same, which indicates a rigid body Additionally, the variations of inter-storey drifts when the top floor witnesses the maximum relative displacements are also displayed in figure 7. Inter-storey drift shows the deformation between the adjacent floors while the relative displacement intuitively reveals the shape of the building. As can be seen in Figure 7, under El-Centro and Hachinohe earthquakes, the passive base isolation system's response is very close to that of the bare building and even larger than it between the 2nd and 3rd floor. On contrast, the inter-storey drift of the frequency controlled base-isolated building much smaller than bare building, showing a superior inter-storey drift reduction performance to the passive base isolation system. motion of the superstructure.

Table 6. Base shear, RMS of acceleration and inter-storey drift of 3 cases under 4 earthquakes

\begin{tabular}{|c|c|c|c|c|c|c|c|c|c|c|c|c|c|}
\hline \multirow{7}{*}{$\begin{array}{c}\boldsymbol{I}_{1} \\
\text { Accel } \\
\text { RMS }\end{array}$} & \multirow{2}{*}{$\begin{array}{c}\text { Floor } \\
\text { No. }\end{array}$} & \multicolumn{3}{|c|}{ El-Centro } & \multicolumn{3}{|c|}{ Kobe } & \multicolumn{3}{|c|}{ Hachinohe } & \multicolumn{3}{|c|}{ Northridge } \\
\hline & & $\begin{array}{c}\text { Bare } \\
\text { (g) }\end{array}$ & $\begin{array}{c}\text { Passive } \\
(\%)\end{array}$ & $\begin{array}{c}\text { Control } \\
(\%)\end{array}$ & $\begin{array}{c}\text { Bare } \\
\text { (g) }\end{array}$ & $\begin{array}{c}\text { Passive } \\
(\%)\end{array}$ & $\begin{array}{c}\text { Control } \\
(\%)\end{array}$ & $\begin{array}{c}\text { Bare } \\
\text { (g) }\end{array}$ & $\begin{array}{c}\text { Passive } \\
(\%)\end{array}$ & $\begin{array}{c}\text { Control } \\
(\%)\end{array}$ & $\begin{array}{c}\text { Bare } \\
\text { (g) }\end{array}$ & $\begin{array}{c}\text { Passive } \\
(\%)\end{array}$ & $\begin{array}{c}\text { Control } \\
(\%)\end{array}$ \\
\hline & 1 & 0.31 & 35.90 & 19.35 & 1.15 & 26.09 & 13.04 & 0.28 & 57.14 & 19.64 & 1.18 & 35.59 & 9.35 \\
\hline & 2 & 0.39 & 27.44 & 17.18 & 1.56 & 20.18 & 10.26 & 0.38 & 44.74 & 15.39 & 1.52 & 29.61 & 7.73 \\
\hline & 3 & 0.47 & 24.92 & 14.89 & 1.89 & 18.52 & 8.73 & 0.46 & 36.96 & 13.22 & 1.85 & 25.20 & 6.59 \\
\hline & 4 & 0.53 & 25.99 & 13.58 & 2.12 & 16.51 & 7.98 & 0.52 & 34.42 & 12.04 & 2.08 & 22.94 & 6.04 \\
\hline & 5 & 0.58 & 27.00 & 12.59 & 2.25 & 29.78 & 7.62 & 0.55 & 32.73 & 11.60 & 2.20 & 21.98 & 5.82 \\
\hline & $\begin{array}{c}\text { Floor } \\
\text { No. }\end{array}$ & $\begin{array}{l}\text { Bare } \\
\text { (g) }\end{array}$ & $\begin{array}{c}\text { Passive } \\
\text { (\%) }\end{array}$ & $\begin{array}{c}\text { Control } \\
(\%)\end{array}$ & $\begin{array}{c}\text { Bare } \\
\text { (g) }\end{array}$ & $\begin{array}{c}\text { Passive } \\
(\%)\end{array}$ & $\begin{array}{c}\text { Control } \\
(\%)\end{array}$ & $\begin{array}{c}\text { Bare } \\
\text { (g) }\end{array}$ & $\begin{array}{c}\text { Passive } \\
\text { (\%) }\end{array}$ & $\begin{array}{c}\text { Control } \\
(\%)\end{array}$ & $\begin{array}{c}\text { Bare } \\
\text { (g) }\end{array}$ & $\begin{array}{c}\text { Passive } \\
(\%)\end{array}$ & $\begin{array}{c}\text { Control } \\
(\%)\end{array}$ \\
\hline$I_{2}$ & 1 & 3.87 & 71.06 & 8.79 & 15.49 & 22.14 & 5.54 & 6.53 & 17.92 & 4.47 & 12.09 & 66.42 & 4.15 \\
\hline Drift & 2 & 1.39 & 104.32 & 13.06 & 5.58 & 32.62 & 8.09 & 2.35 & 26.81 & 6.67 & 4.35 & 96.78 & 6.24 \\
\hline RMS & 3 & 1.12 & 83.93 & 10.54 & 4.50 & 26.01 & 6.50 & 1.89 & 21.32 & 7.46 & 3.51 & 79.71 & 4.97 \\
\hline & 4 & 0.83 & 79.52 & 9.87 & 3.21 & 25.23 & 6.29 & 1.35 & 20.59 & 5.15 & 2.49 & 77.35 & 4.84 \\
\hline & 5 & 0.44 & 82.95 & 10.39 & 1.73 & 31.38 & 6.48 & 0.73 & 21.19 & 5.30 & 1.35 & 79.26 & 4.71 \\
\hline \multirow{2}{*}{\multicolumn{2}{|c|}{ Base $\mathrm{S}$}} & $\begin{array}{l}\text { Bare } \\
(\mathrm{kN})\end{array}$ & $\begin{array}{c}\text { Passive } \\
\text { (\%) }\end{array}$ & $\begin{array}{c}\text { Control } \\
(\%)\end{array}$ & $\begin{array}{l}\text { Bare } \\
(\mathrm{kN})\end{array}$ & $\begin{array}{c}\text { Passive } \\
\text { (\%) }\end{array}$ & $\begin{array}{c}\text { Control } \\
(\%)\end{array}$ & $\begin{array}{l}\text { Bare } \\
(\mathrm{kN})\end{array}$ & $\begin{array}{c}\text { Passive } \\
\text { (\%) }\end{array}$ & $\begin{array}{c}\text { Control } \\
(\%)\end{array}$ & $\begin{array}{l}\text { Bare } \\
(\mathrm{kN})\end{array}$ & $\begin{array}{c}\text { Passive } \\
\text { (\%) }\end{array}$ & $\begin{array}{c}\text { Control } \\
(\%)\end{array}$ \\
\hline & & 13.68 & 124.04 & 34.94 & 49.53 & 46.96 & 27.03 & 22.94 & 79.72 & 14.78 & 44.36 & 17.43 & 11.44 \\
\hline
\end{tabular}

On contrast, the variations of the frequency controlled base-isolated building exhibit a rather similar trend to those of the bare building with much smaller value showing a superior inter-storey drift reduction performance to the passive base isolation system. 
$\boldsymbol{I}_{\mathbf{1}}$ and $\boldsymbol{I}_{2}$ listed in Table 6 represent the RMS of the floor acceleration and inter-storey drift under 4 earthquakes. Since RMS is a statistical measure of the magnitude of a varying quantity showing the data distribution over the statistical range, these indices are able to better evaluate the responses along the entire time history. The RMS acceleration of the building with smart base isolation system is much smaller than that of the passive system in every floor under all four earthquakes. It demonstrates that the controlled system is more effective along the whole time history than the passive system in reducing floor acceleration. A similar phenomenon is observed with the RMS of inter-storey drift, which indicates that the controlled isolation system possesses outstanding performance in that it can reduce peak acceleration and inter-storey drift and protect the building during the entire earthquake duration.

Table 6 also provides the information of base shear force with the index of $\boldsymbol{I}_{3}$. It can be concluded from the value of $\boldsymbol{I}_{3}$ that the passive system displays good potential in minimising the base shear force of the building under Kobe and Northridge earthquakes. However, the base shear wasn't reduced in the Hachinohe earthquake and even was amplified under El-Centro earthquake. Furthermore, the frequency controlled base isolation system has obtained great reduction of shear force compared to both bare building and passive base-isolated building under all 4 earthquakes, which demonstrates that the frequency controlled base isolation system is able to achieve better performance with smaller control forces.

\section{Conclusion}

By employing a novel highly adaptive MRE base isolator whose lateral stiffness can be greatly changed by altering the applied electric current, an innovative smart base isolation system has been developed and studied by the authors. An effective and practical control algorithm derived from the stiffness type selection algorithm for AVS is adopted in light of better exploiting the uniqueness of MRE isolators to implement real-time back forward control of the isolated structure. Extensive simulation has been conducted utilising a five-storey benchmark model. The simulation results demonstrate that compared to bare building and passive base-isolated building models, the smart base-isolated building with the proposed control method demonstrates remarkable performance in minimising acceleration, inter-storey drift and base shear at the same time under different types of earthquake attacks. Such promising performance enlightens the future of the development of smart isolation system employing the MRE base isolator and provides robust supporting evidence for experimental testing for the proposed smart base isolation system.

\section{Acknowledgement}

The authors acknowledge the financial support by Discovery Grant (Grant No. DP150102636) from Australian Research Council and Research Seed Fund
Grant in Faculty of Engineering and Information Technology, University of Technology Sydney.

\section{References}

Jangid RS and Datta TK (1995) Seismic behaviour of baseisolated buildings: a state-of -the-art review. Structures and Buildings 110 (2): 186-203.

Kelly JM (1999) The current state of base isolation in the United States. In: Proceedings of the Second World Conference on Structural Control (ed by T Kobori, Y Inoue, K Seto, H Iemura and A Nichitani), Kyoto, Japan, July 1998, pp.1043-52. Ney York: John Wiley \& Sons

Kim HS, Roschke PN, Lin PY and Loh C (2006) Neurofuzzy model of hybrid semi-active base isolation system with FPS bearings and an MR damper. Engineering Structures 28: 947-581.

Kobori T, Takahashi M, Nasu T, Niwa1 N and Ogasawara K (1993) Seismic response controlled structure with active variable stiffness system. Earthquake Engineering and Structural Dynamics 22: 925-941.

Li Y and Li J (2015) A highly-adjustable base isolator utilizing magnetorheological elastomer: experimental testing and modelling. ASME Journal of Vibration and Acoustics 137(01): 011009.

Li Y, Li J, Li W and Samali B (2013a) Development and characterization of a magnetorheological elastomer based adaptive seismic isolator. Smart Materials and Structures 22(3): 035005.

Li Y, Li J and Samali B (2012) A novel adaptive base isolator utilising magnetorheological elastomer. In: 22nd Australasian Conf. on the Mechanics of Structures and Materials (ed B Samali, M Attard and C Song), Sydney, Australia, 11-14 December 2012, pp.763-781. London: CRC Press, Taylor and Francis.

Li Y, Li J, Tian T and Li W (2013b) A highly adjustable magneto-rheological elastomer base isolator for applications of real-time adaptive control. Smart Material and Structures 22(9): 095020.

Mazza F and Vulcano A (2012) Effects of near-fault ground motions on the nonlinear dynamic response of base-isolated R C framed buildings. Earthquake Engineering and Structural Dynamics 41(2): 211-232.

Padalka O Song HJ, Wereley NM, Filer JA and Bell RC (2010) Stiffness and Damping in Fe, Co, and $\mathrm{Ni}$ Nanowire-Based Magnetorheological Elastomeric Composites., IEEE Transactions on Magnetics 46(6): 2275-2277.

Ramallo JC, Johnson EA and Spencer Jr BF (2002) Smart Base Isolation Systems. Journal of Engineering Mechanics 128(10): 1088-1099.

Spencer BF and Nagarajaiah S (2003) State-of-the-art of structural control. Journal of Structural Engineering 129(7): 845-856.

Symans MD, Cofer WF, and Fridley KJ (2002) Base isolation and supplemental damping systems for seismic protection of wood structures: literature review. Earthquake Spectra 18(3): 549-572. 
Yang Y, Li Y and Li J (2014) Parameter identification of a novel strain stiffening model for magnetorheological elastomer base isolator utilizing enhanced particle swarm optimization, Journal of Intelligent Material Systems and Structures. Epub ahead of print 3 November 2014. DOI: 10.1177/1045389X14556166.

Yang J, Wu J and Li Z (1996) Control of seismic-excited buildings using active variable stiffness systems. Engineering Structures 18(8): 589-596.

Yoshioka H, Ramallo J C and Spencer B F Jr (2002) "Smart" Base Isolation Strategies Employing Magnetorheological Dampers. Journal of Engineering Mechanics 128: 540-551. 